\title{
Quadrangular resection versus chordal replacement for degenerative posterior mitral leaflet prolapse
}

\author{
Jiexu Ma ${ }^{1,2 \#}$, Jian Liu ${ }^{1 \#}$, Peijian Wei ${ }^{1,2 \#}$, Ximeng Yao ${ }^{1,2}$, Yuyuan Zhang ${ }^{1}$, Liangzheng Fang ${ }^{1}$, Zhao Chen ${ }^{1}$, \\ Yanjun Liu ${ }^{1}$, Tong Tan ${ }^{1,2}$, Hongxiang Wu ${ }^{1}$, Huanlei Huang ${ }^{1}$, Bin Xie ${ }^{1}$, Jimei Chen ${ }^{1}$, Jian Zhuang ${ }^{1}$, \\ Huiming Guo ${ }^{1}$
}

${ }^{1}$ Department of Cardiovascular Surgery, Guangdong Provincial Key Laboratory of South China Structural Heart Disease, Guangdong Cardiovascular Institute, Guangdong Provincial People's Hospital (Guangdong Academy of Medical Sciences), Guangzhou, China; ${ }^{2}$ Medical College, Shantou University, Shantou, China

Contributions: (I) Conception and design: H Guo, J Ma, J Liu; (II) Administrative support: J Chen, J Zhuang, H Guo; (III) Provision of study materials or patients: J Liu, H Huang, B Xie, H Guo; (IV) Collection and assembly of data: P Wei, Y Zhang, L Fang, X Yao, Z Chen, Y Liu; (V) Data analysis and interpretation: J Ma, T Tan, H Wu; (VI) Manuscript writing: All authors; (VII) Final approval of manuscript: All authors.

\#These authors contributed equally to this work.

Correspondence to: Huiming Guo. Department of Cardiovascular Surgery, Guangdong Provincial Key Laboratory of South China Structural Heart Disease, Guangdong Cardiovascular Institute, Guangdong Provincial People’s Hospital, Guangdong Academy of Medical Sciences, No. 106, Zhongshan Er Road, Guangzhou 510080, China. Email: guohuiming@vip.tom.com.

Background: The aims of the present study was to compare midterm results of quadrangular leaflet resection versus chordal replacement for the repair of degenerative posterior mitral leaflet (PML) prolapse, and to explore the risk factors for recurrent severe mitral regurgitation (MR).

Methods: From January 2012 to December 2018, 1,423 consecutive patients underwent mitral valve (MV) repair. A total of 317 had degenerative PML prolapse and constituted the study population. Of these, $74(23.3 \%)$ underwent quadrangular leaflet resection, and 243 (76.7\%) underwent chordal replacement. Outcomes were compared by using unadjusted data and propensity score-matched analyses.

Results: Patients with multiple leaflet prolapse were more likely to undergo chordal replacement $(18.4 \%$ vs. $41.9 \%, \mathrm{P}<0.001)$, and performed as a minimally invasive approach (47.3\% vs. $61.7 \%, \mathrm{P}=0.027)$. Of the entire cohort, 1 death $(0.3 \%)$ occurred due to intraoperative aortic dissection, and 1 patient who had undergone chordal replacement required reoperation before discharge for posterior leaflet tearing. There was no significant difference in the probability of freedom from recurrent severe MR at 82 months between the resection and neochordae groups in both the pre-matched $(95.6 \%$ vs. $88.8 \%, \mathrm{P}=0.105)$ and matched (95.2\% vs. 88.5\%, $\mathrm{P}=0.170)$ cohorts, which was consistent across all of the examined subgroups $(\mathrm{P}>0.05)$. Multivariate Cox regression indicated that dilated left ventricular end-systolic diameter (LVESD) was an independent risk factor for recurrent severe $\mathrm{MR}[<40 \mathrm{vs}$. $>40 \mathrm{~mm}$, hazards ratio (HR): 3.17, 95\% confidence interval (CI): 1.20-8.39, $\mathrm{P}=0.020]$; however, surgical technique was not (resection vs. neochordae, HR: 0.31, 95\% CI: $0.07-1.37, \mathrm{P}=0.122)$.

Conclusions: Chordal replacement for the repair of degenerative posterior MV prolapse yields similar satisfactory outcomes when compared with quadrangular resection, and is promising in minimally invasive cardiac surgery for various lesions. However, it is also associated with more recurrent severe MR, albeit nonsignificant, for which patients with dilated LVESD are at high risk.

Keywords: Degenerative mitral disease; posterior leaflet prolapse; mitral valve repair (MV repair); leaflet resection; chordal replacement

Submitted Oct 21, 2020. Accepted for publication Dec 08, 2020.

doi: 10.21037/atm-20-7475

View this article at: http://dx.doi.org/10.21037/atm-20-7475 


\section{Introduction}

Isolated posterior leaflet prolapse is the most common abnormality seen in degenerative mitral regurgitation (MR), and is the main etiology of mitral valve (MV) disease in Western countries, which is gradually becoming prevalent worldwide $(1,2)$. MV repair is increasingly used to restore leaflet morphology and left ventricular (LV) function due to its excellent long-term outcomes, and is the recommended treatment in clinical guidelines (3-7). Leaflet resection and chordal replacement are repair techniques that continue to evolve. The quadrangular resection of prolapsed scallop in annuloplasty with ring implantation, as part of the famous "French correction", was once the standard technique for the repair of degenerative posterior mitral leaflet (PML) prolapse $(8,9)$. This technique aims to reconstruct normal anatomy and dimensions, in context that the resection of excessive or thickened leaflet could decrease surface tension and hence prevent the mitral leaflet from accelerating degenerative disorder, especially for patients with advanced myxomatous change or Barlow's disease $(8,10)$. However, the resection technique has been found to affect mobility and consistency, resulting in the potential poor performance of $\mathrm{LV}$ function after surgery $(11,12)$. The chordal replacement technique, which was initially used in anterior mitral leaflet prolapse (13), became widely used in PML repair and an alternative to preserving complete tissue $(14,15)$. As a means of functional restoration, chordal replacement was devised to maintain normal geometry and movement of the valvular apparatus throughout the cardiac cycle, therefore permit better ventricular performance (6). But the excess leaflet going along with billowing, is the result of the pathologic process sometimes, of which that reservation may leads to concerns about adverse events like systolic anterior motion (SAM) and recurring leaflet prolapse (16).

Although excellent short- and long-term outcomes have been reported by previous studies $(2,6)$, underlying differences at follow-up between these two techniques with opposite principle remain, as well as risk factors for MR recurrence. A recently published article tried exploring this question, with a relatively small sample size and mostly covering patients with single segmental prolapse, while those with multi-segmental disease were prevalent but overlooked (17). Besides, with mainly focus on perioperative outcomes rather than long-term events, probe into the cause of relapse was insufficiency. Therefore, the aim of the present study was to compare the results of quadrangular resection compared with chordal replacement for the repair of degenerative PML, with a focus on the recurrence of severe MR.

We present the following article in accordance with the STROBE reporting checklist (available at http://dx.doi. org/10.21037/atm-20-7475).

\section{Methods}

\section{Patients}

From January 2012 to December 2018, 1,423 consecutive patients underwent MV repair at the Department of Cardiovascular Surgery of Guangdong Provincial People's Hospital (Guangzhou, China). Surgical indications were based on the guidelines from ACC/AHA, which suggest surgery for severe primary mitral regurgitation with class I, $\mathrm{IIa}$, IIb recommendations depending on clinical situations. A total of 488 patients were excluded from present study due to non-degenerative underlying etiology, and 32 were excluded due to clear diagnosis of coronary heart disease. Patients with anterior mitral leaflet prolapse $(n=258)$, commissural leaflet prolapse $(\mathrm{n}=23)$, or bi-leaflet prolapse $(\mathrm{n}=215)$, and those who had undergone both techniques $(\mathrm{n}=10)$ or neither quadrangular resection nor chordal replacement $(n=80)$ were also excluded. Of the 317 remaining patients who met the inclusion criteria, 74 had undergone plasty with quadrangular resection and 243 had undergone chordal replacement and were allocated to the resection group or neochordae group, respectively (Figure 1).

This study was conducted in accordance with the Declaration of Helsinki (as revised in 2013). Institutional review board approval from the Ethics Committee of Guangdong Provincial People's Hospital (GDREC2020252H) was obtained for this analysis together with the patient consents.

\section{Surgical technique}

Surgeries were either conventional sternotomy or minimally invasive. The $4-\mathrm{cm}$ working port and $1.2-\mathrm{cm}$ assistant port in the fourth intercoastal space around right the anterior axillary line were used in most of the minimally invasive mitral surgeries, as previously described (18). The choice of repair technique was based on the surgeon's decision. All patients underwent annuloplasty with ring implantation with interrupted sutures. 


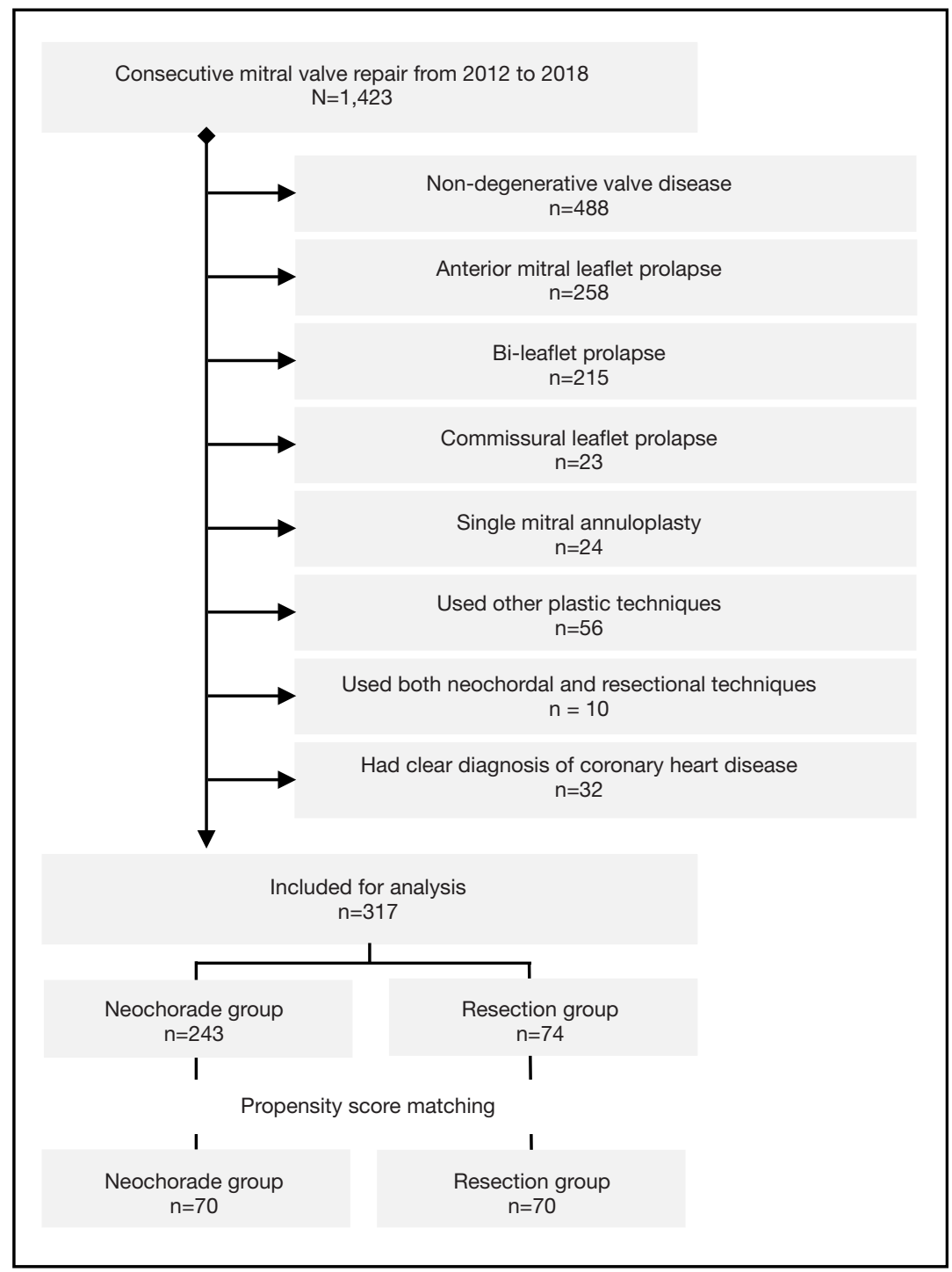

Figure 1 Flow diagram of patient selection.

\section{Chordal replacement}

For chordal replacement, a 4-0 or 5-0 expanded polytetrafluoroethylene (ePTFE) GORE-TEX suture (W. L. Gore \& Associates, Inc, Flagstaff, Arizona, USA) with a gasket was mainly used. The suture's double arm would first cross the fibrous tip of the corresponding papillary muscle respectively and be secured to it with a knot. Next, the suture was passed through the free margin of the prolapsed segment of the posterior leaflet 2-3 times, and was tied down on the atrial side after adjusting the length (19). For multiple segmental leaflet prolapse, the loop and loop-in-loop techniques were applied instead of several independent artificial chordae (20,21). The estimated length from preoperative transesophageal echocardiography (TEE) or intraoperative caliper measurement using the nearest normal native chordae tendineae as reference, was prioritized when setting the length of the artificial chordae $(22,23)$. Saline injection permitted further careful adjustment.

\section{Quadrangular resection}

To remove the prolapsed or redundant posterior leaflet, a standard quadrangular resection was used $(6,8)$. In most cases, detaching the quadrangular prolapsed leaflet from the 
annulus and sewing 2 edges together was sufficient. If the remaining leaflets were of significantly different heights or $>20 \mathrm{~mm}$ in length, the sliding or modified sliding technique was used to reduce height and tension (24). Occasionally, artificial chordae replacement was applied to correct residual partial prolapse; these cases were not included in the present study prevent further heterogeneity.

\section{Parameters studied}

Baseline information and clinical data were extracted from medical records saved in the hospital information registry. Preoperative data included age, sex, body mass index, presence of comorbidities (e.g., history of stroke, hypertension, diabetes, renal failure, atrial fibrillation), New York Heart Association (NYHA) functional classification (I-IV), MR grade (none, mild, moderate, severe), and echocardiographic data (Figure 2). The valvular lesion was confirmed by intraoperative exploration. The location and numbers of prolapsed segments were recorded. Secondary aortic cross-clamping events referred to residual MR following cardiopulmonary bypass (CPB), and further correction following a second cardiac arrest was considered necessary. Perioperative complications during hospitalization were also recorded.

The first follow-up visit was 3 months following hospital discharge. Clinic or telephone follow-ups were then conducted annually. The aim of the follow-up visit was on adverse events, in particular, death, recurrent MR, reoperation, stroke, and permanent pacemaker implantation. The end-point event was a composite of severe MR or MV reoperation. The follow-up ended on December 30, 2019.

\section{Statistical analysis}

Continuous variables were summarized as mean \pm standard deviations or medians for distribution, and frequencies and proportions for categorical variables. Wilcoxon's rank sum test was used for comparisons between continuous and ordinal variables, and Pearson's $\chi^{2}$-test or Fisher's exact test were for categorical variables. All tests were 2 tailed and the results were considered significant if $\mathrm{P}<0.05$.

To reduce the confounding factors that are inherent in observational studies, we matched patients based on their propensity score. For each patient, the probability of undergoing quadrangular resection was calculated using a non-parsimonious multivariable logistic regression, in which the covariates included were those that may contribute to the occurrence of end-point events and choice of surgical technique, or those that presented significantly different between two groups after univariable analysis $(11,17,25)$. Next, patients treated with quadrangular resection were matched 1:1 to patients treated by chordal replacement using a greedy nearest neighbor matching strategy under a caliper width of 0.10 . This resulted in a well-balanced cohort (Figure 3).

Kaplan-Meier survival curves [log-log transformation for confidence interval (CI)] were used to estimate eventfree survival probabilities using the Breslow test to detect statistical differences, as most adverse events occurred in the early stage. For the primary end-point, multivariable Cox proportional hazards model was constructed to explore potential risk factors. Candidate variables included those that were considered clinically relevant or those that were significantly associated with recurrent severe $M R$ after univariable analysis, with a threshold of $\mathrm{P}<0.20$. Given the quantity of available end-point events, this model was based on the pre-matched cohort. The proportional hazards assumption was considered to be satisfactory in this model, and referred to the visual examination of the Kaplan-Meier curve and $\log$ (minus log) curve without cross-over.

Several subgroup analyses were performed in the pre-matched cohort to assess potential heterogeneity of treatment effect on primary outcomes. Separate Cox models were applied to these subgroups, which included age (cut-off of the median: 53 years), sex (male vs. female), surgical approach (minimally invasive $v s$. conventional), number of diseased segments (single $v s$. multi-segments), and left ventricular end-systolic diameter (LVESD) (cutoff: $40 \mathrm{~mm}$ ). Hazards ratio (HR), 95\% CI, and P value for interactions were reported.

All statistical calculations were carried out with $\mathrm{R}$ (version 4.0.2; R Foundation for Statistical Computing, Vienna, Austria).

\section{Results}

\section{Patient baseline characteristics}

Patient baseline characteristics are summarized in Table 1. The median age at surgery was 53 years [interquartile range (IQR), 44-60 years] for the total study cohort, and 117 patients were female (36.9\%). Preliminary analysis showed that the pre-matched cohort already had tolerable comparability. The neochordae group was significantly associated with greater multiple segmental 

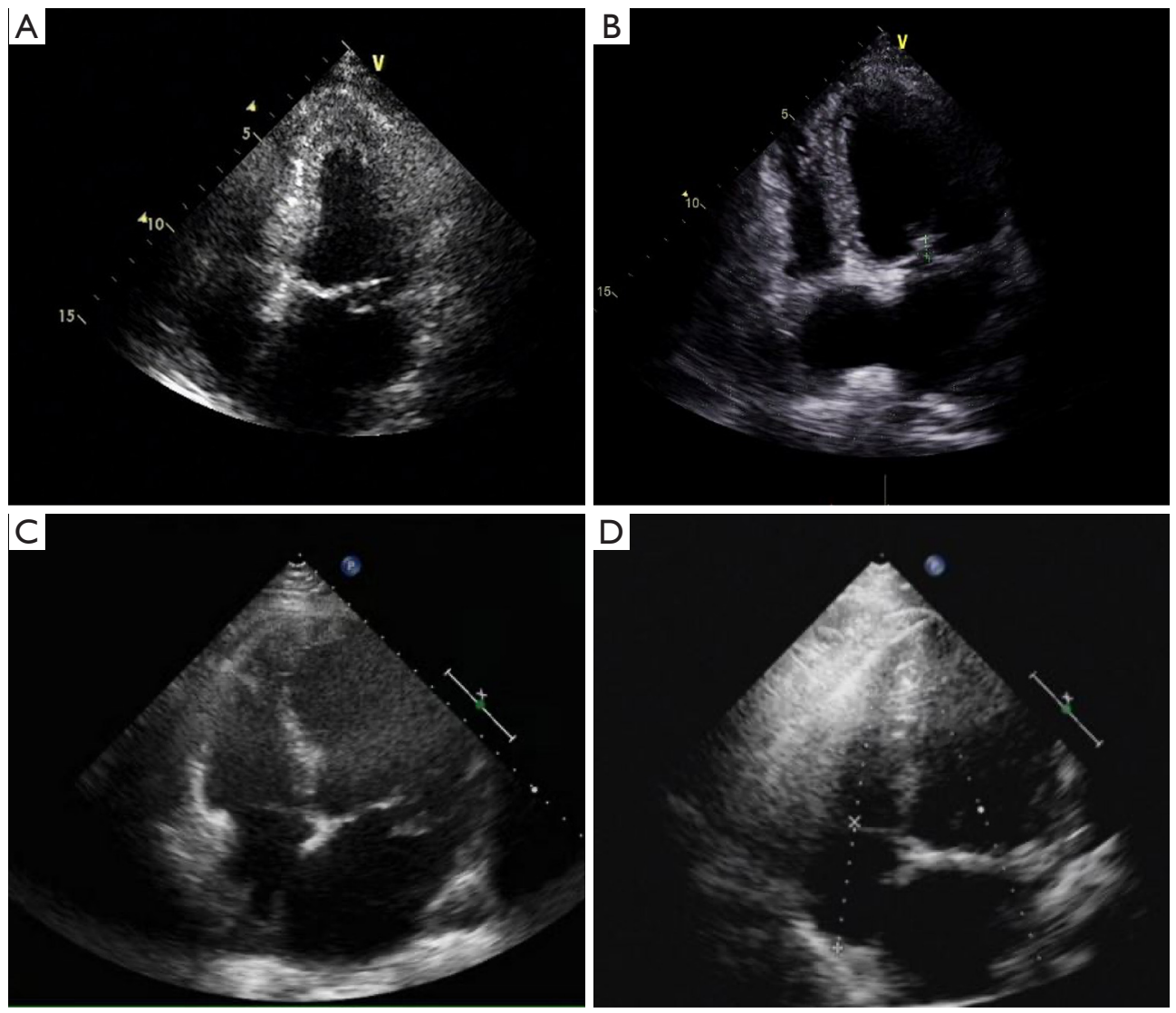

Figure 2 The Apical four-chamber view in transthoracic echocardiogram. The pre-operative (A) and post-operative TTE (B) from the patient in neochordae group. The pre-operative (C) and post-operative TTE (D) from the patient in resection group.

prolapse $(18.4 \%$ vs. $41.9 \%, \mathrm{P}<0.001)$ and minimally invasive cardiac surgeries $(47.3 \%$ vs. $61.7 \%, \mathrm{P}=0.027)$ compared with the resection group. These imbalances were used in the propensity score matching model, and a reduced standardized mean difference and a well-proportioned distribution of propensity score were observed. No differences in NYHA functional class, MR grade distribution, and echocardiographic measurements were observed between the groups. Leaflet prolapse involving the P2 segment was the most common prolapse (68.7\%).

\section{Surgical and postoperative details}

An overview of the surgical characteristics and postoperative details is shown in Table 2. Operative time, aortic crossclamp time (ACC), and CPB time of the resection group were significantly shorter compared with the neochordae group in the pre-matched cohort, but only the difference of ACC $(69.87 \pm 20.75$ vs. $75.16 \pm 19.60 \mathrm{~min}, \mathrm{P}=0.032)$ reached statistical significance in the matched cohort, mainly because of the correction in the distribution discrepancy of patients with multiple diseased segments and the reduction in the sample size after matching. The implanted annuloplasty ring size was similar between groups, while the postoperative echocardiogram demonstrated a larger coaptation height in the neochordae group $(7.25 \pm 1.63 \mathrm{vs}$. $7.76 \pm 1.78 \mathrm{~mm}, \mathrm{P}=0.048$ ), though no statistical difference was observed after matching $(7.26 \pm 1.65$ vs. $7.58 \pm 1.87 \mathrm{~mm}$, $\mathrm{P}=0.226$ ). Two patients in the resection group and 1 in the neochordae group required a second pump run for the treatment of residual MR found by TEE following CPB (2.9\% vs. $1.4 \%, \mathrm{P}=1.00)$. There were no significant differences in the length of intensive care unit stay [39.73 $\pm 26.07 \mathrm{~h}$ (median: $22 \mathrm{~h}$ ) vs. $42.48 \pm 46.62 \mathrm{~h}$ (median: $33 \mathrm{~h}), \mathrm{P}=0.569]$, mechanical ventilation time $[12.16 \pm 8.13 \mathrm{~h}$ (median: 10 h) vs. $14.00 \pm 18.30 \mathrm{~h}$ (median: $10 \mathrm{~h}$ ), $\mathrm{P}=0.892$ ], and the application of blood transfusion (18.6\% vs. $11.4 \%$, $\mathrm{P}=0.237)$. One patient in the neochordae group $(1.4 \%)$ 
Distribution of Propensity Scores

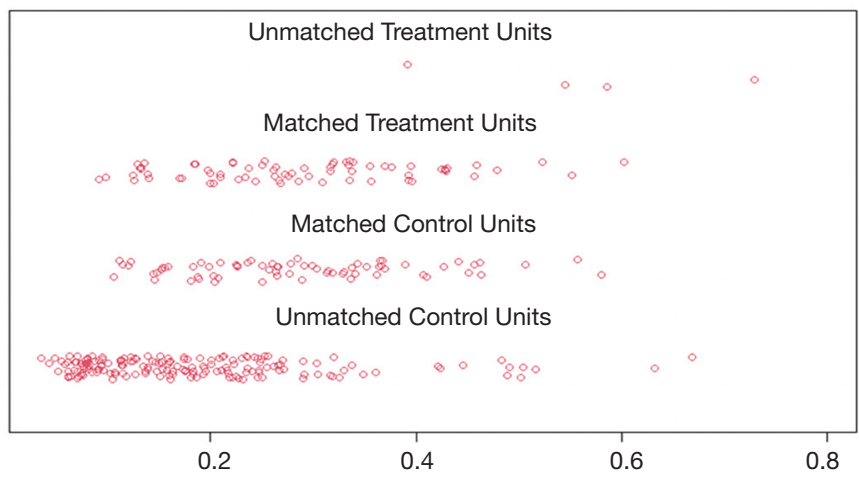

Number of segments diseased-

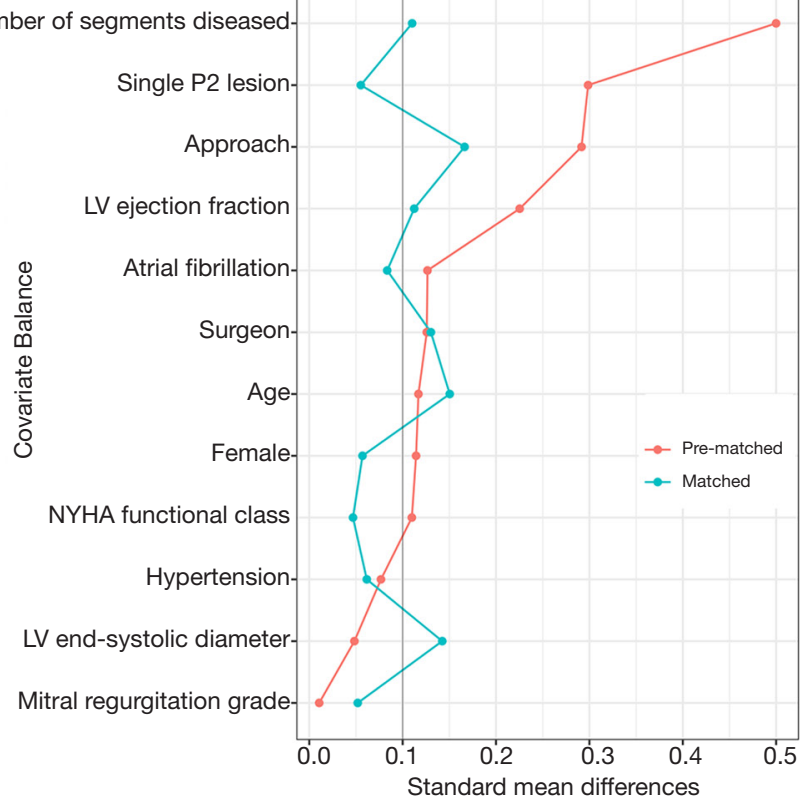

Figure 3 Propensity score matching. (A) Scatterplot of distribution of propensity scores. (B) Standard mean differences for baseline covariates comparing the resection group with the neochordae group in the pre-matched and matched samples. LV, left ventricular; NYHA, New York Heart Association.

died in hospital due to intraoperative aortic dissection; this was the only patient death in the entire cohort $(0.3 \%)$. The probability of complications was extremely low and comparable between groups.

\section{Recurrent MR and MV reoperation}

The median follow-up for the entire cohort was 32 months (IQR: $18-50$ months), with a follow-up rate of $92.7 \%$. Event-free survival probabilities of recurrent severe MR in the resection and neochordae groups were 95.6\% (95\% CI: $81.7-99.0 \%, 82$ months) and 88.8\% (95\% CI: 82.8-92.8\%, 95 months) in the unmatched cohort, $95.2 \%$ (95\% CI: $80.1-98.9 \%, 82$ months) and $88.5 \%$ (95\% CI: 75.4-94.9\%, 91 months) in the matched cohort, respectively (Figure 4). None of these differences were statistically significant. Of note, all recurrent severe MR was recorded before 39 months, resulting in the curves being steady at a later period.

Of the 22 patients who had end-point events ( 2 in the resection group and 20 in the neochordae group), 3 underwent $M V$ reoperation: 1 patient underwent re-repair surgery before discharge for earlier MV failure (tear of posterior leaflet confirmed in intraoperative exploration, neochordae group), 1 for recurrent P3 segment prolapse (neochordae group) and one for new-onset P2 segment prolapse (resection group). The other 19 patients had transthoracic echocardiogram (TTE) to identify the lesions; 14 revisited our center and underwent echocardiogram to determine the cause of severe MR. Of these, 1 patient was from the resection group (poor coaptation) and the other 13 were from the neochordae group [ 1 for systolic anterior motion (SAM), 7 for recurrences of original segment prolapse, 1 for artificial chordae fracture, 1 for new-onset A1 segment prolapse, 1 for new-onset P1 segment prolapse, and 2 for poor coaptation].

In the exploratory subgroup analysis, the effect of the surgical techniques on recurrent severe MR was also noted across all the subgroups examined. A trend toward better outcomes in the resection group is shown in Figure 5, although this trend was not statistically significant. No significant heterogeneity between surgical technique and any of the covariates was observed ( $\mathrm{P}$ value for interaction was $>0.05$ for all comparisons). In addition, the multivariable Cox model revealed that LVESD was the independent risk factor for recurrent severe MR (<40 vs. $\geq 40$ mm, HR: $3.17,95 \%$ CI: 1.20-8.39, $\mathrm{P}=0.020$ ); however, surgical technique (resection vs. neochordae, HR: 0.31, 
Table 1 Baseline characteristics and valvular pathophysiology

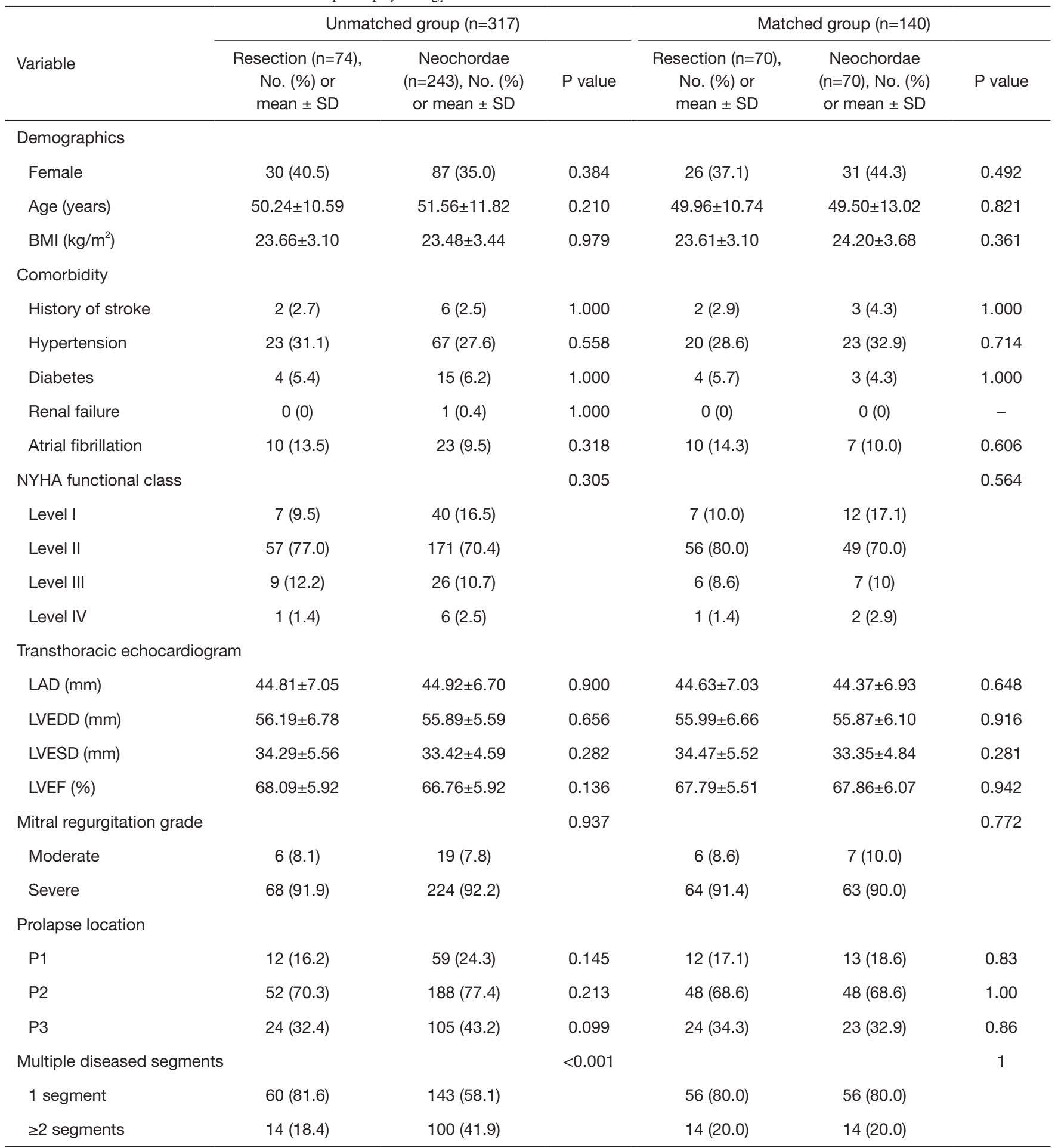

BMI, body mass index; LAD, left atrial diameter; LVEDD, left ventricular end-diastolic diameter; LVEF, left ventricular ejection fraction; LVESD, left ventricular end-systolic diameter; NYHA, New York Heart Association; SD, standard deviation. 
Table 2 Operative details and perioperative complications

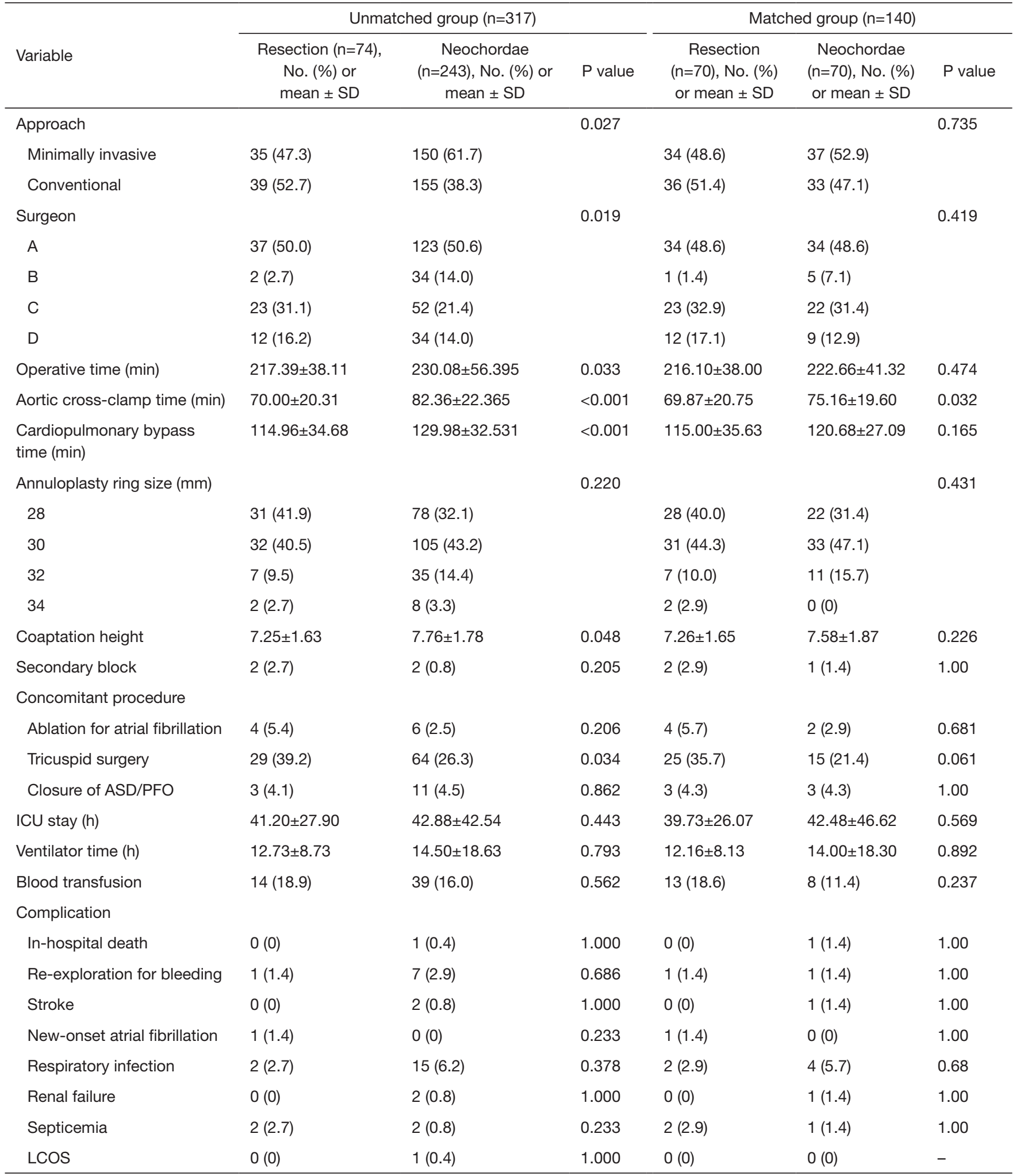

ASD, atrial septal defect; PFO, patent foramen ovale; ICU, intensive care unit; LCOS, low cardiac output syndrome; SD, standard deviation. 
A

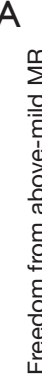
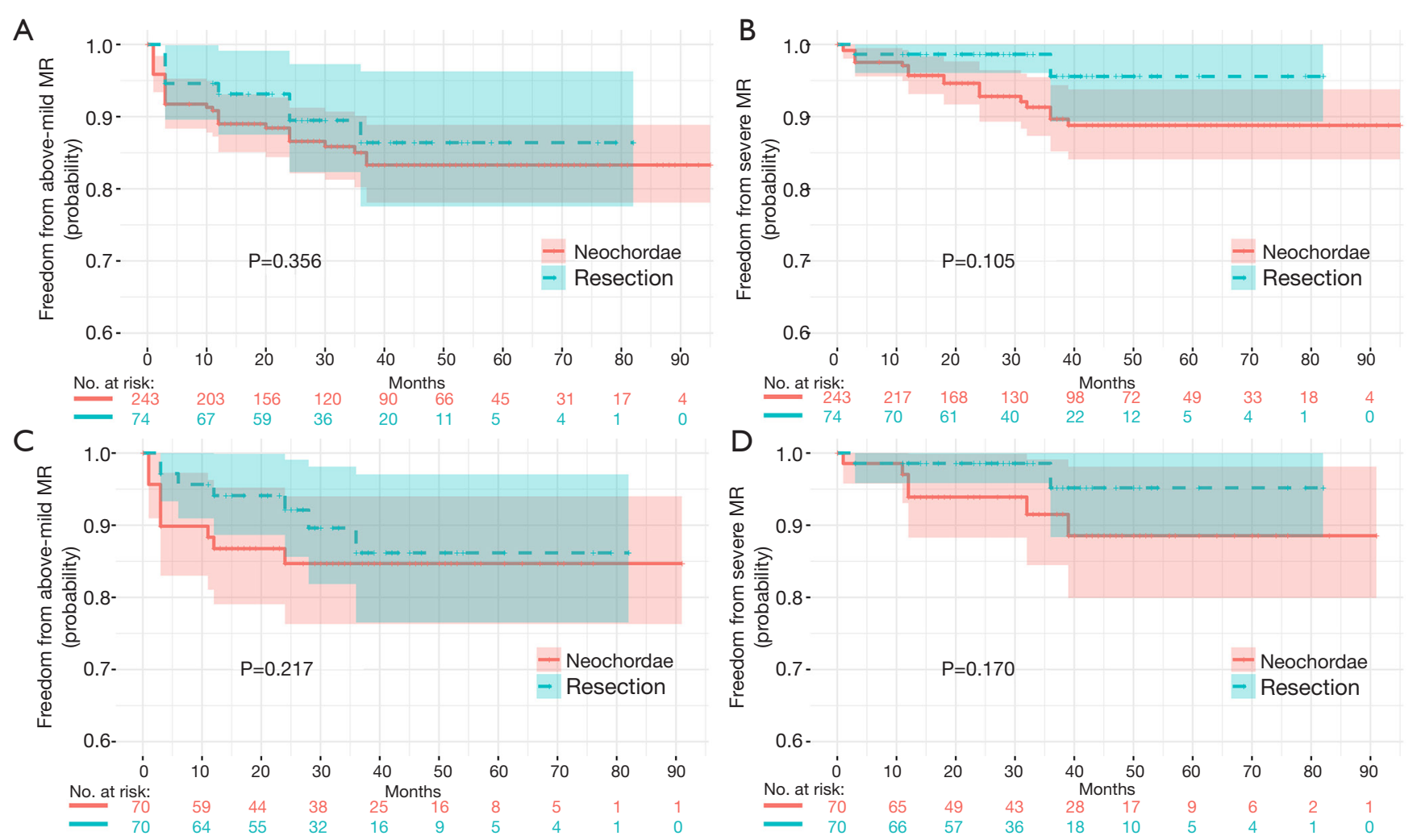

Figure 4 Probability of freedom from recurrent above-mild (moderate or severe) mitral regurgitation (MR) in the unmatched comparison (A), recurrent severe MR in unmatched comparison (B), recurrent above-mild MR in matched comparison (C), and recurrent severe MR in matched comparison (D).

95\% CI: 0.07-1.37, P=0.122) was not (Table 3).

\section{Long-term mortality and complications}

As shown in Table 4, from the entire cohort, there was 1 patient with detected SAM in each group. A total of 4 patients had stroke after discharge, of which 2 were of hemorrhagic (both in the neochordae group) and 2 were ischemic (1 per group). The only all-cause death recorded was in the resection group. Permanent pacemaker was required in 2 patients: 1 from the neochordae group for third-degree atrioventricular block, and 1 from the resection group for frequent ventricular tachycardia with a family history of sudden death. Surgical technique did not significantly affect the incidence of adverse events.

\section{Discussion}

In the context of pathological diversity in degenerative mitral disease, quadrangular resection is preferred for those with redundancy myxomatous leaflet and continuous lesions, while chordal replacement is the treatment of choice for those with elongation or rupture of the supporting chordae. However, the former was outperformed in clinical application by the latter, which was found to be more reproducible and simpler for repair procedures (26). In our center, chordal replacement was increasingly performed for patients with multiple prolapses or advanced myxomatous lesions. This could also explain the significantly shorter total operative time of $\mathrm{CPB}$ and $\mathrm{ACC}$ in the resection group being closer to that of the neochordae group when narrowing the baseline difference of leaflet lesions by propensity score matching (Tables 1 and 2). Similarly, Pasrija et al. found that chordal repair was utilized by $98 \%$ of patients undergoing MV repair for degenerative MR (2). The resection technique will cause irrevocable structural change of mitral leaflet, while the artificial chordae can be withdrawn and reset, which makes the chordal replacement technique be suitable for any kind of degenerative MR $(2,23)$. Premeasured loops further simplify the process of 


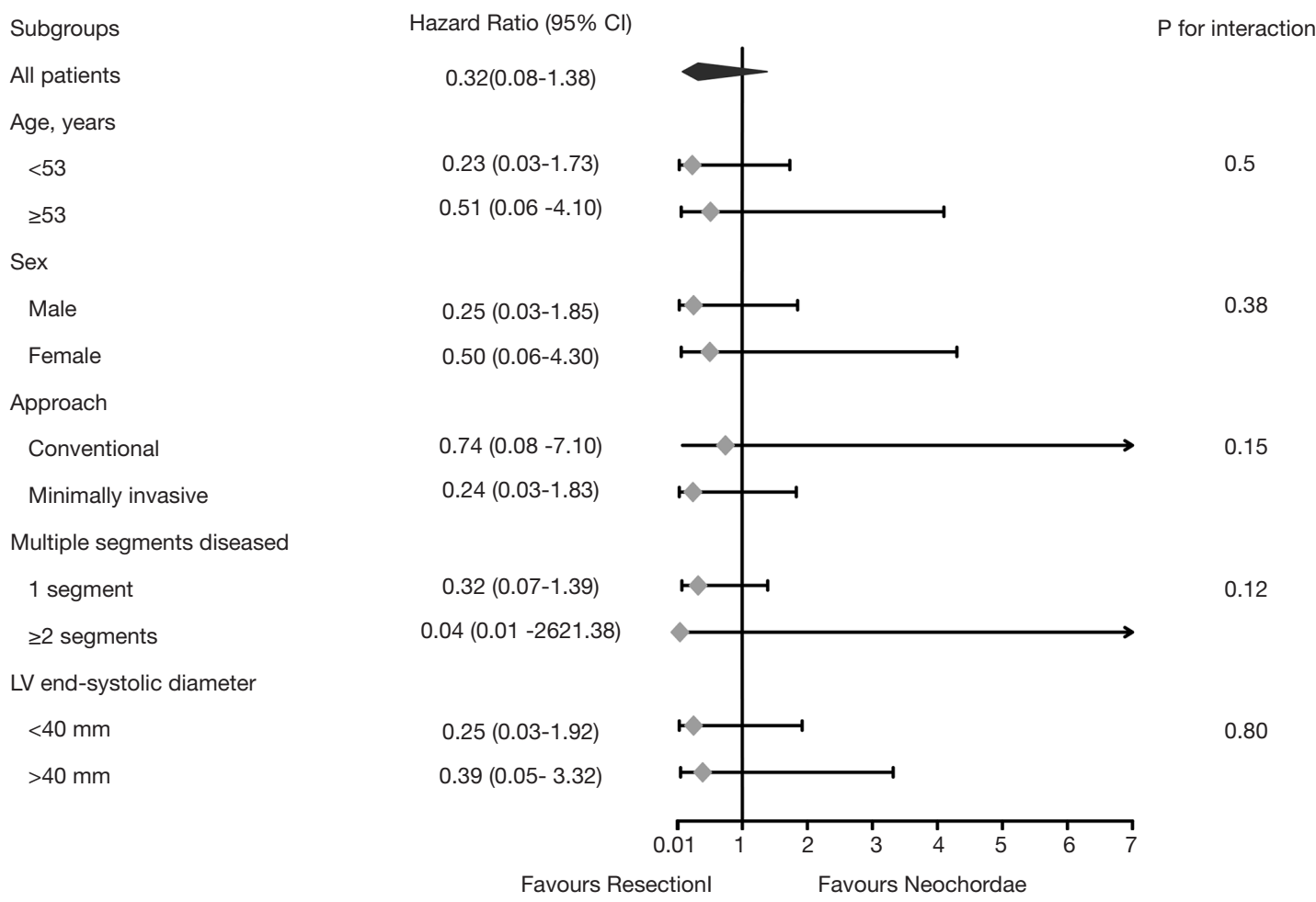

Figure 5 Forest plot depicting hazard ratios of quadrangular resection versus chordal replacement for repair of degenerative posterior mitral leaflet prolapse. CI, confidence interval; LV, left ventricular.

chordal replacement for multiple prolapse, especially in the setting of minimally invasive cardiac surgery (27). Of note, nowadays, when treating patients with Barlow's disease, we would prefer combing chordal replacement with resection technique. Placing a large annuloplasty ring or folding the leaflet were once used to evenly flatten the billowing leaflet, however, were questioned because of the non-physiologic correction (16). Appropriately reducing the excess height of posterior leaflet could effectively reshape the morphology, and reduce the tension on native and artificial chordae (28).

For a long time, the durability of normal valvular function after repair appealed to cardiac surgeons' attention and always be the main focus in studies. In the present study, the rate of freedom from recurrent severe MR in the resection and neochordae groups was $95.6 \%$ and $88.8 \%$ at 6.8 years, respectively (Figure $4 B$ ). A similar outcome was observed in the matched comparison (Figure $4 D$ ). These results were partially comparable with those from previous studies, such as that of Lange et al., who had a $96 \%$ rate for quadrangular resection and $95 \%$ for chordal replacement at 4 years (29). According to David et al.'s study of 606 patients, chordal replacement led to a freedom from recurrent severe MR rate at 10 and 18 years of $96.5 \% \pm 0.8 \%$ and $91 \% \pm 2.7 \%$, respectively (30). In the present study, the neochordae group did not have such superior outcomes. The non-significant trend toward increased recurrent severe MR in the neochordae group highlighted the possible shortcoming of our chordal replacement technique (Figure 4). Of the 14 recurrences of severe MR in the neochordae group confirmed by operative exploration or TTE in our center, recurring prolapse accounted for $71.4 \%$ (10/14), including 8 in original segments and 2 in newonset segments. Although we could not clearly distinguish that the prolapses in same scallop were caused by either degenerative progression or inharmonious artificial chordae, the physiological function and morphology of $M V$ was found to be steady after surgical correction in this degenerative disease $(27,30)$.

To repair a localized prolapse with limited width, we built a pair of artificial chordae using a double-armed ePTFE suture positioned near the centra. The artificial chordae and the excess leaflet tissue would conduce to forming a large coaptation area, which may prevent MR when some adjacent native chordae were diseased and the 
Table 3 Univariate and stepwise multivariate Cox hazard analysis of risk factors for recurrent severe mitral regurgitation

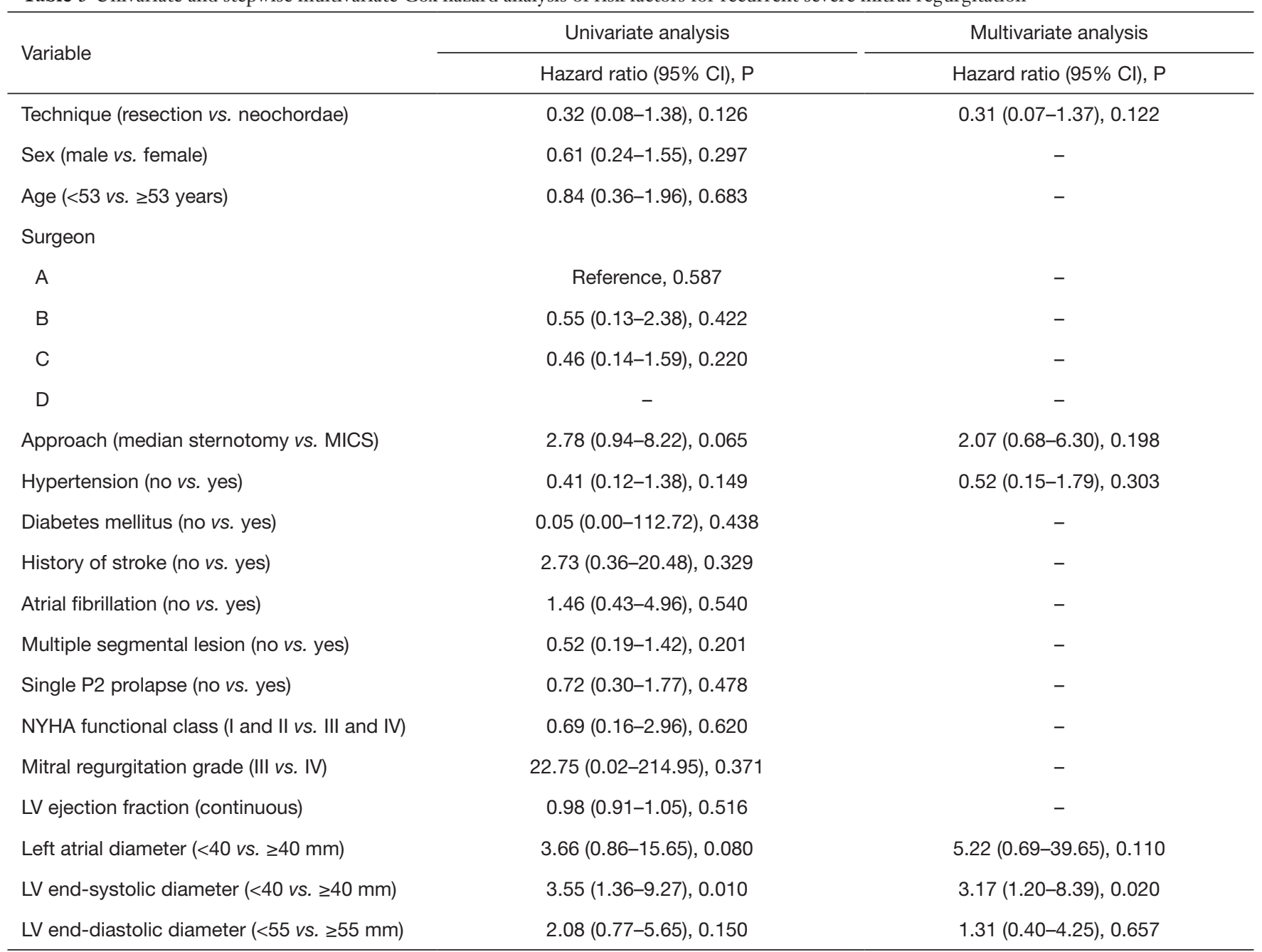

$\mathrm{Cl}$, confidence interval; LV, left ventricular; MICS, minimally invasive cardiac surgery; NYHA, New York Heart Association.

Table 4 Adverse events at follow-up

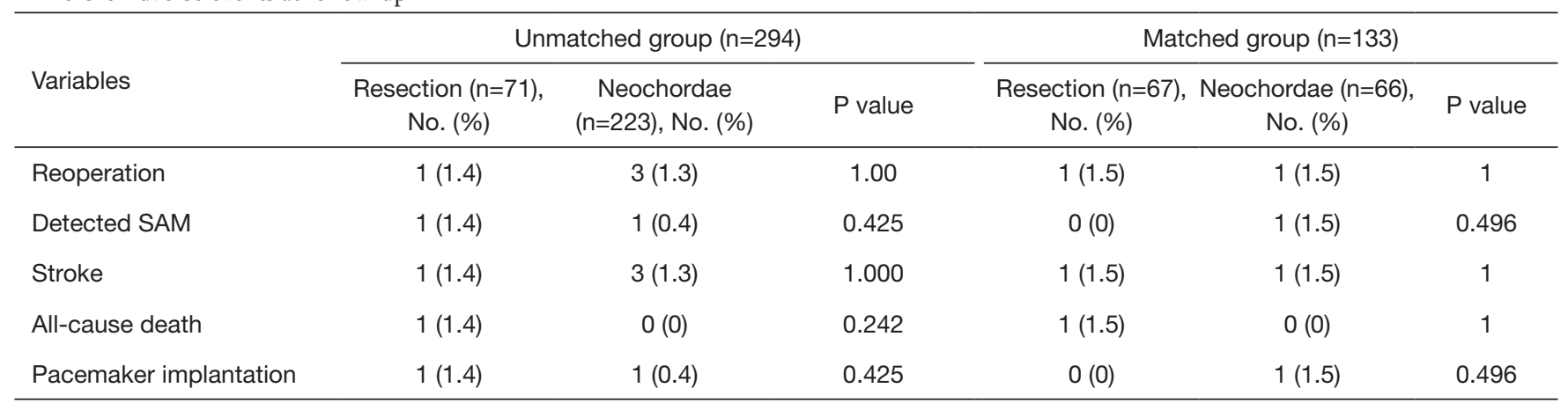

SAM, systolic anterior motion. 
structure were partly changed (31). But the balance would be broken if one or more native diseased chordae were ruptured or elongated following surgery, and hence might cause recurrent leaflet prolapse and severe MR. That fitted with our results that original segmental prolapse was the primary trouble. The more comprehensive and refined reconstruction of mitral apparatus is needed. David et al. suggested adding an artificial chordae at the level where the native chorda is normal and creating a pair of chordae for each $2-3-\mathrm{mm}$ free margin until reaching the other end of the prolapsed segment, and placing an chordae in the area of normal chordae, with a $13 \pm 9$ chordae per repaired valve comprising both anterior and PML prolapse, efficaciously preventing original lesions from recurring prolapse (30). Their remarkable technique fully equilibrated the tension in chordaes and reconstructed the entire prolapsed segment. That reminded us considering mitral valve apparatus as a whole is of great important in stabilizing the MV structure after correction. As more chordal replacement being used in mitral valve repair, the comprehensive assessment of entire mitral apparatus should always come first. And of the prolapsed leaflet, all chordaes should be considered for the needs of rebuilt.

Furthermore, our study demonstrates that LVESD enlargement $\geq 40 \mathrm{~mm}$ is a positive predictor of recurrent severe MR (Table 4). This is comparable to the findings of Kitai et al. and the 2014 and 2017 American College of Cardiology/American Heart Association Guidelines for the management for valvular disease $(32,33)$. They are also in accordance with those of Suri et al., who suggested MV repair in patients before LVESD $>40 \mathrm{~mm}$ (34). Nevertheless, delayed referral of dilated cardiac cavities and annulus is sometimes inevitable. Chordal replacement was proven to provide better valve function and leaflet kinematics, and had similar hemodynamical change after repair of acute posterior MV prolapse when comparing to leaflet resection (15). But the long-term effects on LV restoration still could not be determined (34). In their systematic review and metaanalysis, Mazine et al. reported that chordal replacement may lead to improved postoperative $\mathrm{LV}$ function compared with leaflet resection, based on greater postoperative LV ejection fraction $(+3.4 \%, \mathrm{P}=0.03)$; however, this was only found to be significant in one randomized controlled trial involving 129 patients (11). In contrast, decreased LVESD after surgery was confirmed in several previously published studies $(12,17,32)$. This finding, coupled with the fact that the severe recurring MR were mostly caused by leaflet prolapse of the original repaired scallop, raises the question that whether the artificial chordae is too long to maintain the leaflet at the normal level after LV remodeling. When performing the rising transapical off-pump MV repair with chordae implantation, it is important to set out the chordae with slight over-tensioning to prevent recurrent MR, as the $\mathrm{LV}$ axis dimension decreases during reverse remodeling, even if intraoperative minimal residual MR exists $(35,36)$. The long-term results of this novel technique may provide a new viewpoint to evaluate suitable chordal length.

\section{Limitations}

The present study had several limitations. First, the inherent weakness of observational studies led to potential selection bias, information bias, and incompletion of data, although propensity score matching and subgroup analysis were performed to support our findings. Second, interval censored data was inevitable in this survival analysis, as progressive MR might not cause symptoms and might not be found until subsequent follow-up TTE. Patients from all over China accepted TTE in multiple ultrasonic departments; therefore, the method of measurement and the interpretation of the results might not be consistent, which brought great difficulties to further analysis of cardiac remodeling.

\section{Conclusions}

Quadrangular leaflet resection and chordal replacement for the repair of degenerative posterior MV prolapse yield similar excellent short- and mid-term outcomes. In the era of minimally invasive cardiac surgery, chordal replacement is a more promising technique that is capable of repairing various pathologies. However, it has a trend, albeit nonsignificant, toward more recurrent severe MR after repair by artificial chordae, which highlight the importance of modification of surgical details for better durability. In addition, patients with dilated LVESD are at high risk of recurrent severe MR.

\section{Acknowledgments}

Funding: This research was supported by the Grant of Guangdong Provincial People's Hospital (2017zh06), Science and Technology Planning Project of Guangdong Province (No. 2018B090944002, 2019B020230003), Guangdong peak project (DFJH201802), Science and Technology Program of Guangzhou (202002030039). 


\section{Footnote}

Reporting Checklist: The authors have completed the STROBE reporting checklist. Available at http://dx.doi. org/10.21037/atm-20-7475

Data Sharing Statement: Available at http://dx.doi. org/10.21037/atm-20-7475

Conflicts of Interest: All authors have completed the ICMJE uniform disclosure form (available at http://dx.doi. org/10.21037/atm-20-7475). The authors have no conflicts of interest to declare.

Ethical Statement: The authors are accountable for all aspects of the work in ensuring that questions related to the accuracy or integrity of any part of the work are appropriately investigated and resolved. The study was conducted in accordance with the Declaration of Helsinki (as revised in 2013). Institutional review board approval from the Ethics Committee of Guangdong Provincial People's Hospital (GDREC2020252H) was obtained for this analysis together with the patient consents.

Open Access Statement: This is an Open Access article distributed in accordance with the Creative Commons Attribution-NonCommercial-NoDerivs 4.0 International License (CC BY-NC-ND 4.0), which permits the noncommercial replication and distribution of the article with the strict proviso that no changes or edits are made and the original work is properly cited (including links to both the formal publication through the relevant DOI and the license). See: https://creativecommons.org/licenses/by-nc-nd/4.0/.

\section{References}

1. Nkomo VT, Gardin JM, Skelton TN, et al. Burden of valvular heart diseases: a population-based study. Lancet 2006;368:1005-11.

2. Pasrija C, Tran D, Ghoreishi M, et al. Degenerative Mitral Valve Repair Simplified: An Evolution to Universal Artificial Cordal Repair. Ann Thorac Surg 2020;110:464-73.

3. Hendrix RJ, Bello RA, Flahive JM, et al. Mitral Valve Repair Versus Replacement in Elderly With Degenerative Disease: Analysis of the STS Adult Cardiac Surgery Database. Ann Thorac Surg 2019;107:747-53.

4. Coutinho GF, Antunes MJ. Mitral valve repair for degenerative mitral valve disease: Surgical approach, patient selection and long-term outcomes. Heart 2017;103:1663-9.

5. Lazam S, Vanoverschelde JL, Tribouilloy C, et al. TwentyYear Outcome after Mitral Repair Versus Replacement for Severe Degenerative Mitral Regurgitation: Analysis of a Large, Prospective, Multicenter, International Registry. Circulation 2017;135:410-22.

6. Cubero-Gallego H, Hernandez-Vaquero D, Avanzas P, et al. Outcomes with percutaneous mitral repair vs. optimal medical treatment for functional mitral regurgitation: systematic review. Ann Transl Med 2020;8:962.

7. Baumgartner H, Falk V, Bax JJ, et al. 2017 ESC/EACTS Guidelines for the management of valvular heart disease. Rev Esp Cardiol (Engl Ed) 2018;71:110.

8. Carpentier A. Cardiac valve surgery--the "French correction”. J Thorac Cardiovasc Surg 1983;86:323-37.

9. Javadikasgari H, Mihaljevic T, Suri RM, et al. Simple versus complex degenerative mitral valve disease. J Thorac Cardiovasc Surg 2018;156:122-9.e16.

10. Thubrikar M, Piepgrass WC, Bosher LP, et al. The elastic modulus of canine aortic valve leaflets in vivo and in vitro. Circ Res 1980;47:792-800.

11. Mazine A, Friedrich JO, Nedadur R, et al. Systematic review and meta-analysis of chordal replacement versus leaflet resection for posterior mitral leaflet prolapse. J Thorac Cardiovasc Surg 2018;155:120-8.e10.

12. Pascual I, Benito-González T, Hernandez-Vaquero D, et al. Percutaneous treatment with Mitraclip for functional mitral regurgitation: medium-term follow up according to left ventricular function. Ann Transl Med 2020;8:959.

13. Lawrie GM, Earle EA, Earle NR. Feasibility and intermediate term outcome of repair of prolapsing anterior mitral leaflets with artificial chordal replacement in 152 patients. Ann Thorac Surg 2006;81:849-56.

14. Perier P, Hohenberger $W$, Lakew F, et al. Toward a New Paradigm for the Reconstruction of Posterior Leaflet Prolapse: Midterm Results of the "Respect Rather Than Resect” Approach. Ann Thorac Surg 2008;86:718-25.

15. Padala M, Powell SN, Croft LR, et al. Mitral valve hemodynamics after repair of acute posterior leaflet prolapse: Quadrangular resection versus triangular resection versus neochordoplasty. J Thorac Cardiovasc Surg 2009;138:309-15.

16. Dreyfus GD, Dulguerov F, Marcacci C, et al. "Respect when you can, resect when you should": A realistic approach to posterior leaflet mitral valve repair. J Thorac Cardiovasc Surg 2018;156:1856-66.e3. 
17. Ma K, Chen A, Wang Z, et al. Chordal replacement versus quadrangular resection in degenerative posterior mitral leaflet repair. J Thorac Dis 2019;11:827-38.

18. Ma J, Liu J, Yuan H, et al. Two-port thoracoscopic myectomy for hypertrophic cardiomyopathy with threedimensional printing. Ann Thorac Surg 2020. [Epub ahead of print]. doi: 10.1016/j.athoracsur.2020.05.183.

19. DAVID TE. Replacement of Chordae Tendineae with Expanded Polytetrafluoroethylene Sutures. J Card Surg 1989;4:286-90.

20. Seeburger J, Falk V, Borger MA, et al. Chordae Replacement Versus Resection for Repair of Isolated Posterior Mitral Leaflet Prolapse: À Ègalité. Ann Thorac Surg 2009;87:1715-20.

21. Okamoto K, Yozu R, Kudo M. Loop-in-loop technique in mitral valve repair via minithoracotomy. Ann Thorac Surg 2012;93:1329-30.

22. Doi A, Iida H, Sunazawa T. Intracardiac Calipers for Artificial Chordae Replacement in Mitral Valve Repair. Ann Thorac Surg 2009;87:326-8.

23. David TE, David CM, Lafreniere-Roula M, et al. Longterm outcomes of chordal replacement with expanded polytetrafluoroethylene sutures to repair mitral leaflet prolapse. J Thorac Cardiovasc Surg 2020;160:385-94.e1.

24. Gillinov AM, Cosgrove DM. Modified quadrangular resection for mitral valve repair. Ann Thorac Surg 2001;72:2153-4.

25. Mihaljevic T, Pattakos G, Gillinov AM, et al. Robotic posterior mitral leaflet repair: Neochordal versus resectional techniques. Ann Thorac Surg 2013;95:787-94.

26. David TE, Armstrong S, McCrindle BW, et al. Late outcomes of mitral valve repair for mitral regurgitation due to degenerative disease. Circulation 2013;127:1485-92.

27. Holubec T, Sündermann SH, Jacobs S, et al. Chordae replacement versus leaflet resection in minimally invasive mitral valve repair. Ann Cardiothorac Surg 2013;2:809-13.

28. Imbrie-Moore AM, Paulsen MJ, Zhu Y, et al. A novel

Cite this article as: Ma J, Liu J, Wei P, Yao X, Zhang Y, Fang L, Chen Z, Liu Y, Tan T, Wu H, Huang H, Xie B, Chen J, Zhuang J, Guo H. Quadrangular resection versus chordal replacement for degenerative posterior mitral leaflet prolapse. Ann Transl Med 2021;9(1):60. doi: 10.21037/atm-20-7475 cross-species model of Barlow's disease to biomechanically analyze repair techniques in an ex vivo left heart simulator. J Thorac Cardiovasc Surg 2020. [Epub ahead of print]

29. Lange R, Guenther T, Noebauer C, et al. Chordal Replacement Versus Quadrangular Resection for Repair of Isolated Posterior Mitral Leaflet Prolapse. Ann Thorac Surg 2010;89:1163-70.

30. David TE, Armstrong S, Ivanov J. Chordal replacement with polytetrafluoroethylene sutures for mitral valve repair: A 25-year experience. J Thorac Cardiovasc Surg 2013;145:1563-9.

31. Colli A, Besola L, Montagner M, et al. Prognostic impact of leaflet-to-annulus index in patients treated with transapical off-pump echo-guided mitral valve repair with NeoChord implantation. Int J Cardiol 2018;257:235-7.

32. Kitai T, Okada Y, Shomura Y, et al. Timing of valve repair for severe degenerative mitral regurgitation and longterm left ventricular function. J Thorac Cardiovasc Surg 2014;148:1978-82.

33. Nishimura RA, Otto CM, Bonow RO, et al. 2017 AHA/ ACC Focused Update of the 2014 AHA/ACC Guideline for the Management of Patients With Valvular Heart Disease: A Report of the American College of Cardiology/ American Heart Association Task Force on Clinical Practice Guidelines. J Am Coll Cardiol 2017;70:252-89.

34. Suri RM, Enriquez-Sarano M, Schaff H V. Preservation of left ventricular function after degenerative mitral valve repair: Refocusing on timing, techniques, and teaching. J Thorac Cardiovasc Surg 2015;150:448-9.

35. Carnero-Alcázar M, Cobiella-Carnicer J, Mahia-Casado P, et al. Combined off-pump mitral repair and thoracoscopic maze surgery. Asian Cardiovasc Thorac Ann 2020. [Epub ahead of print]

36. Colli A, Adams D, Fiocco A, et al. Transapical NeoChord mitral valve repair. Ann Cardiothorac Surg 2018;7:812-20.

(English Language Editor: R. Scott) 